SYSTEMIC REVIEW

\title{
UTILIZING ELECTROPHYSICAL AGENTS IN FIBROMYALGIA - A REVIEW
}

\begin{abstract}
BACKGROUND

Fibromyalgia (FM) frequently termed as fibrositis is a discomforting rheumatic syndrome which is associated with spasm, localize and palpable tenderness, chronic fatigue, headache, depression and bowel symptoms. The use of electro physical agents in order to treat FM is still a growing concern. A systematic review was executed to appraise the use of different electro physical agents in FM.
\end{abstract}

\section{METHODS}

Seventy three articles were reviewed including RCTS, Clinical trials and Experimental studies, highlighting the use of electro physical agents and comparing them with each other.

\section{CONCLUSION}

Fibromyalgia is a syndrome is challenging to comprehend and treat effectively. Patients are looking for substitution therapies due to ineffectiveness and dissatisfaction to the conventional and therapies in trend. Although many results have been found in favor of using different modalities related to physical therapy treatment for FM still specific use of modalities like TENS, biofeedback, magneto and electromagnetic therapies is still a question. Treatment should be given according to the need of patient, targeted symptoms and functional impairments.

\section{KEY WORDS}

Fibromyalgia, TENS, IFC, Heat, Cold, Laser, Ultrasound
M. Usman Khan

Senior Lecturer

Ziauddin College of Physical Therapy

Ziauddin University

m_khanusman@hotmail.com

\section{Sumaira Imran Farooqui}

Associate Professor

Principal

Ziauddin College of Physical Therapy Ziauddin University

sumairaimranfarooqui@gmail.com

\section{Amna Aamir Khan}

Assistant Professor

Ziauddin College of Physical Therapy

Ziauddin University

akhan39@caledonian.ac.uk
[Khan MU, Farooqui SI, Khan AA. Utilizing Electrophysical Agents in Fibromyalgia: A Review Pak. j. rehabil. 2014;3(2):3-10] 


\section{INTRODUCTION}

FM is characterized as syndrome with wide spread body-ache, muscular tenderness, tendons, joint junctions and other soft tissues. It has been related to fatigue, insomnia, depression, anxiety and sometimes headaches. Usually tenderness found at 11 of 18 precise muscle-tendon sites $^{1}$. As research conducted on fibromyalgia shows that around $2 \%$ of the general population suffers from fibromyalgia, where men are affected 10 times less than women². In a few researches a hypotheses has been recently developed that FM is a psychologically neuro-endocrine, psychiatric or a psycho- somatic disorder, that may be linked with depression ${ }^{3}$, it may also involve the disturbance of cytokines in the body or its inflammatory response $e^{4,5}$. There may be exaggerated inflammatory responses in FM syndromes or increase receptor activity to pain ${ }^{6}$. Currently, extensive variety of options is available for the treatment of FM. Nevertheless, the consensus for the treatment choices is still unidentified ${ }^{7}$. Different types of therapies are evolving for the treatment of FM, different school of thoughts are working on pharmaceutical treatment while others on traditional physiotherapy treatments including laser and acupuncture while psychological treatments remain in trend 8,9 . As the etiological factors of FM are still obscure, immense effort is placed on the long term relieving effects of $F M^{10}$

After looking at the current facts no specific treatments are available which can decrease the ailments. The traditional painkillers and muscle relaxants have been used since many years to decrease the signs and symptoms of FM but no noteworthy work has been done on the long term and permanent relief of FM. However, a wide variety of treatment strategies are available that can help in temporary relief. While in contrast to traditionally used drug treatments, physiotherapy helps in improving the QOL of a patient suffering from $\mathrm{FM}^{11}$. An increase in the awareness regarding the adverse effects of orally ingested pain killers and muscle relaxants have initiated the search of alternative treatment regimes. Most of the time alternative treatment procedures are taken as naturally relieved therapies that have little or no adverse effect on the long term health status of the patient. Physical therapy is widely being utilized as an alternative therapy by not only focusing on reduction of pain but also helping in the areas of deconditioning, muscle weakness, and insomnias. One of the researches indicates that over $91 \%$ patients are looking for alternative therapies and only $9 \%$ were taking drug treatments ${ }^{12}$.

\section{METHODOLOGY}

Five articles were reviewed including RCTs, Clinical trials and Experimental studies. Comparative studies, double blind placebo controlled trial were also considered for the review. These studies emphasized on the use of electro physical agents and comparing them with each other. The studies selected for the review either had a single intervention or a combination therapy of two modalities. These studies selected the use of ultrasound, TENS, acupuncture, laser therapy, IFC, and electromyography biofeedback training. Richard et al, evaluated the patients in OPD, patients $(n=164)$ were divided into 6 weeks program with a follow-up to 6 months in a multidisciplinary program, they found the changes in quality of life, satisfaction level of patients, pain and functional activities and consequences by using the patients questionnaires and clinical evalua- tion in combination. On the other hand Pioro-Boissetet et $\mathrm{al}^{12}$ evaluated $80 \mathrm{FM}$ patients through questionnaire and found that the two-third of the FM patients was using alternative medications and multiple interventions. Different Studies ${ }^{10-12}$ measured the reliability of Infrared Laser therapy with a Placebo laser on trigger points of healthy students, twice each point, and that Infrared Laser therapy give better results than placebo laser.

These studies conducted focused on the electro therapeutic treatment of patients having fibromyalgia and other musculoskeletal problems.

There are many other situations like stroke rehabilitation stroke lower back pain etc, can be treated with electrotherapeutic modalities. Further research is likely to uncover additional areas where electrotherapy interventions will be useful.

In this review, we have regarded the existing and current work done on FM and the use of different Electro and physical agents such as heat therapy, Cryotherapy, ultrasonic waves, Tens acupuncture therapy.

\section{HEAT THERAPY}

Kelly Rehan ${ }^{13}$ explained heat therapy as the most ideal maneuver for the diminution of chronic aches and pains linked with fibromyalgia. As when heat is applied it relaxes the muscle which in turn speeds up the blood flow, that allows extra blood to carry extra oxygen and nutrients which triggers the body's natural healing process. Heating may not eliminate the reason of pain, but it can successfully ease the pain. Heating tissues or het therapy can be done through dry heating that is using electrical heating pads, hot water bottles etc or moist heating treatments through steam or by moist or warm cloth'3. Baranowsky et al $^{14}$ (2009), they conduct a RCT to identify and evaluate the quality and effects of complementary and alternative medicine (acupuncture, balneotherapy, thermotherapy, magnetic therapy). The ACR criteria for FM was published in 1990, they have investigated from 1990s to july 2007 .Encouraging consequences were also recorded for mild infrared hyperthermia in $1 \mathrm{RCT}^{14}$. - Hot packs are effectual in conditions related to inflammation as it effectively improves blood circulation and lessen pain which is a condition in fibromyalgia. Whirlpool and Jacuzzi jet massaging therapy also plays vital role in the treatment of fibromyalgia. The writer also explains a type of soothing warmth therapy 'Waon' that produce far infrared ray, dry sauna bath concluding the significant and positive outcomes on pain reduction to the patients involved in the study ${ }^{15}$.

\section{COLD THERAPY}

Swenson et al (1996) wrote an article in which he highlighted the effects of cryotherapy. Cold therapy is as old as the Middle Ages, where it was used as an anesthesia preoperatively by the Roman physician Galen. During 4th century B.C The Greek physician Hippocrates wrote that cold therapy was used to control inflammation and in relieving pain thus lessens swelling. Ernst, End. A Fialka, gave scientific evidence from clinical trials that cold therapy may reduce the nerve conduction, resulting in decreases muscle spasms, and hinder edema subsequent to injury ${ }^{16}$ peer, K.P., Warren, R.F. and Horowitz L. worked on the 
Randomized control trail NAMES OF AUTHOR AND DESCRIPTION: RICHARD S6

THIS STUDY IS ABOUT THE TREATMENT OF FIBROMYALGIA SPEER $K^{17}$

THIS STUFY ID ABOUT EFFICIACY OF CRYOTHERAPY IN FROZEN SHOULDER AND ELBOW SURGERIES BERMAN BM ${ }^{39}$ THIS STUDY IS ABOUT THE ACCUPUNCTURE TREATMENT OF FIBROMYALGIA

Survey based study NAMES OF AUTHOR AND DESCRIPTION: PIORO- BIOSSET M ${ }^{12}$ THIS STUDY IS REGARDING ALTERNATIVE MEDICINE IN FIBROMYALGIA SYNDROME GUR A. KARAKOC $M^{58}$ THIS STUDY IS ABOUT LOWER POWER LASER THERAPY AND EXERCISES OF PAIN AND FUNCTION WITH PATIENTS HAVING CHRONIC BACK PAIN

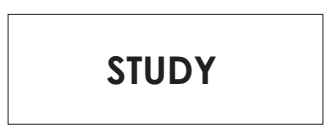

SYSTEMATIC REVIEW NAMES OF AUTHOR AND DESCRIPTION: LEHMAN J19 THIS STUDY IS ABOUT HEATING OF JOINT STRUCTURES BY APPLYSING THERAPEAUTIC ULTRASOUND
CLINICAL TRAIL MESTER E ${ }^{68}$ THE BIO STIMULATIVE EFFECT OF LASER BEAM
Random sampling NAMES OF AUTHOR AND DESCRIPTION: WOLFE F ${ }^{2}$ THIS STUDY IS ABOUT THE PREVALNCE AND CHARACTERISTICS OF FIBROMYLGIA IN GENERAL POPULATION postoperative shoulder and estimated the importance of the effects of cryotherapy by using VAS. This prospective study included 50 consecutive. By postoperative day $10^{17}$. On examination the inflammation reported to be reduces in patients who were receiving cryotherapy treatment and thus the pain on VAS reduced. A study conducted by Matsushita $\mathrm{K}$ et al explained that the waon therapy is effective in fibromyalgia. Patients experienced a signifi- 
cant reduction in pain ${ }^{18}$.

\section{ULTRASOUND}

In the field of physical therapy ultrasound has been acknowledged as the best modality to reduce the musculoskeletal pain symptoms whether acute or chronic. With the experimental studies it has been proved that we can heat deeper structures with ultrasound like bone, joints and muscles by using $1 \mathrm{MHz}$ frequency ${ }^{19}$. The main characteristic of fibromyalgia is pain, but there is a controversy in sustaining the position of muscles in pathogenesis by controlled studies. Muscle deconditioning and focal sustained contraction have been explained by perfusion and metabolic changes. The function of pulse ultrasound therapy is to improve muscle performance by rising the permeability of the cell membrane it then improves intracellular energy utilization in turn increase angiogenesis in ischemic tissues repair ${ }^{20}$. An observational prospective cohort study was conducted on 20 FM patients, and received soft tissue manipulations in combination with ultrasound therapy; they observed the reduction in the intensity of pain. Also the complaints of non- recuperative sleep decreased thus showed enhancement in efficient behavior ${ }^{21}$. A study conducted by Almeida and subordinates suggested the use of combination therapy of ultrasound and interferential current, which gives an effective way for the treatment of pain and sleep pattern improvement in FM patients 22 .

\section{TENS AND IFC (INTERFERENTIAL CURRET)}

TENS is the most commonly used current that produce analgesia electronically. The mode and process of pain relief through TENS is still obscure. Pain is the most common condition that recommended the use of TENS. The latest research work has hypothesized that by the stimulating the brain stem nuclei or sympathetic nervous system endorphins can be release and it may also constrain the inflammatory pains due to arthritic conditions. The rate of success of the use of TENS in different domains has found to be vary between $25 \%-90 \%{ }^{23}$. The use of TENS in FM is limited as it is characterized as the generalized musculoskeletal pain. However in some musculoskeletal problems the justification of the use of TENS in different other conditions is also available on the basis of clinical data. The domestic use of portable TENS can b on an advantage. The significant results for the usage of TENS also depend on the criteria of instruction followed and monitoring of its $\mathrm{use}^{24}$. There have been controversial results obtained in FM with the use of TENS and electro-acupuncture techniques. According to one study combination therapy of ultrasound and IFC showed an valuable affect so it makes ultrasound and TENS as a precious modality in physical therapy which gives an effective way to treat pain and solve the insomniac condition in FM patients ${ }^{22}$. Di Benedetto $P$ et al. have done the only study to appraise a non-pharmacological in contradiction of a pharmacological intervention TENS to be mediocre to adenosyl-Lmethi- onine (an antidepressant) on 3 of the 13 outcomes evaluated ${ }^{25}$. They found no significant changes in terms of pain, sleep patterns and functional status. The follow up of this study was only 6 weeks and because of this it limits the value of this finding. De Domenico describes the IFC as a low frequency, amplitude modulated current that is produced by intersecting two medium frequency currents having different carrier frequencies. IFC behaves like TENS and helps in promoting analgesic effects by pain gate mechanism. The pain alleviation by IFC can be understand by the proposed pain gate theories, which explains that the blockade of the nociceptive stimuli in the dorsal horn of the spinal cord occur, and thus the $A \beta$ myelinated fibers stimulated and results in the blockage of $C$ amiyelinated nociceptive afferents, as well as it enhances the release of opioid analgesic ${ }^{22}$.

\section{MAGNETO THERAPY AND ELECTROMAGNETIC FIELD}

Magneto therapy is the use of magnetic energy to alleviate the pain, the lodestones have been used anciently, a natural sources of magnetism. Likewise, the electrical energy and electrical rays were used for the treatment of pain anciently by Egyptians, Romans and Greeks. Later on these were symbolized as the basis for the use of electrical and magnetic energies to alleviate pain. Mesmer and Hell were the first one who have used permanent magnets over the painful regions and found dramatic results. Currently, in this era, many of the medical conditions have been treated though the use of static magnets in the form of braces, chain, necklaces and bands, along with the pulsed therapies, and its use is interestingly increasing day by day ${ }^{26}$. Now a days researchers are using electromagnetic techniques on infants. As investigators use randomized, placebo controlled designs with better endpoints, and the usage of static magnetic field for cervical pains. A precaution must be taken while treating with static magnets that the magnet should be kept at least 6 inches away from the pace makers ${ }^{27}$. The pain can be reduced and relieved by the use of Pulsed electromagnetic field therapy, by the removal of toxins because of increasing blood supply to the region. Trock examined that while treating post-polio syndrome patients by targeting the tender points through static magnetic therapy and observed better results than placebo in transient pain relief (19\% vs $76 \%$ ) by Mc Gill pain score questionnaire. It has been hypothesized that $C$ fiber neurons can be desensitized by the use of magneto therapy and thus helps in relieving pain ${ }^{28}$.

\section{ELECTROMYOGRAPHIC BIOFEEDBACK TRAINING}

Biofeedback is the emerging technology use in order to train a body function similar to the voluntary action. It teaches specific to develop consciousness of processes and sensations that are not usually noticeable, and make them in the voluntary control with the use of biofeedback equipment. When using a biofeedback equipment on an individual, it measures physiological variables such as heart rate, skin temperatures, and pressures on the skin surface. The equipment is able to detect minute's changes in measurements, and if it detects a minute change it can encourage the patient to correct it. After sometime the purpose of biofeedback is to distinguish these changes deprived of the help of equipment. It is an approach that has been used to enhance the control of physiological activities by the non-physiological response. Electromyography (EMG) biofeedback is extensively been used and is reinforced by many of the researchers, clinicians and therapists and have also a wide variety of literature ${ }^{23}$. Ferracioli et al. examined 15 subjects in an open- trial and examines that patients with FM can considerably treated and benefited by the use of EMD techniques ${ }^{29}$. There is 
$50 \%$ improvement noticed in 9 patients over 6 months. In one the study done by Buckelew et al. on biofeedback training he demonstrated that after giving 6 weeks procedure the short and long term benefits in 119 FM patients have been achieved ${ }^{30}$. The use of EMG biofeedback is like an adjunct in a multidisciplinary treatment procedure, but still the exact mechanism is unknown ${ }^{23}$. A study by Molina et al Proved that there is a reduction in plasma ACTH and endorphin (morphine like substance in the body) by using EMG biofeedback treatment and found beneficial ${ }^{31}$. One of the studies suggests that the patients who do not have psychopathological problems get benefit from Electromyography biofeedback ${ }^{32}$.

\section{ACCUPUNCTURE}

The use of acupuncture therapy by needling has been approved and implemented by the national institute of health conference presumed that needle therapy may be valuable as an aide and option for patients with FM or it might be incorporated in a complete administration program $^{33}$. Writing studies have surveyed the logical confirmation of the utilization of needle therapy in the treatment of $\mathrm{FM}^{23}$. Some randomized, controlled and companion studies have been distributed that demonstrate the helpful impact of needle therapy for patients with $\mathrm{FM}^{34-36}$. One of the preferences of needle therapy is the lower frequency of antagonistic impacts, contrasted and that of numerous medications ${ }^{33}$. Results from a randomized controlled trial reported that FM patients accepting electro needle therapy experienced noteworthy change in both subjective torment lessening also, target increment of torment edge contrasted with patients accepting sham electro needle therapy. Yet, there are couple of high caliber controlled studies to backing its broad utilization ${ }^{37,38}$. Bermen et al. also examined that there is a likelihood of decreasing pain by using needle therapy ${ }^{39}$. Deluse et al. performed a high caliber, randomized Study with 70 patients with $\mathrm{FM}^{37}$, he applied 6 needles for 3 weeks, and found significant re results in 5 of 8 result measures that were VAS, quality of rest, torment edge, and pain reliving techniques as contrasted and a sham electro Needle therapy bunch. While $70 \%$ of the subjects receiving the electro needle therapy shows positive results in relieving pain then the control group bundle. As demonstrated by the Deluse, electro needle treatment may Transform into a fruitful subordinate framework for FM. Regardless of the way that needle treatment has all the reserves of being decently protected, precautionary measures must be taken while using the needle technique ${ }^{40}$. Needle treatment was associated with 29 Patients with FM ( 25 women and 4 men). The results found in the investigation concerning the serum levels of serotonin and Substance $P$ prescribe that needle treatment can propel changes in the centralization of torment directing substances. In addition, researchers viewed reductions in the amount of masochist Sensitive centers and reduced VAS scores contrasting with Patients' own specific reports of torment reduction in patients with FM Treated with needle treatment in a non-controlled 6-week study. In another study, Sprott et al. evaluated 20 patients With FM using needle treatment that was balanced by every tolerant pre requisites after a specific tradition $^{41}$. The five most Basic fragile centers were evaluated by laser flowmetry likewise, the data were differentiated and temperature estimation. Similarly, dolorimetry extended circulatory system was selected beforehand each one of the sensitive concentrates after needle treatment was associated. The number of sensitive centers was lessened from 16.1 to 13.8 after treatment. These data prescribe that needle treatment is useful in the treatment of FM. In a cross-over arranged pilot consider by Sandberg et al. Including 10 to 14 needle treatment sessions showed Change in sensitive point number ${ }^{41}$. In this study, seventy-eight Percent of all patients had brief misery easing, 33\% Continued having desolation lightening at 2 to 3 months. General Diminishing in desolation, in light of calm's examination of around the world Treatment effect, kept setting off simply up to 8 weeks. Regardless, in a little subgroup of patients, reduction of musculoskeletal desolation in Focal locales persevered past that timeframe, until the climax of 24-weeks of postliminary. As needs be, disregarding change With 10 to 14 needle treatment session, reduction of signs was brief and no-solid overall change was distinguished. Sandberg et al. moreover displayed that one needle Impelling (needle treatment) into the premier tibia muscle and Overlying skin fabricates close-by skin and muscle circulatory system in FM patients. Significant needle impelling makes a more unmistakable Extension to just implanting the needle subcutaneously ${ }^{42}$. In any case, the significant system for needle induction moreover induces more anguish and uneasiness to the patients, which should be considered in the middle. As opposed to FM patients, strong Subjects don't respond to subcutaneous needle insertion with extended skin or muscle circulatory system ${ }^{42}$. Waylon is finished a study with electro needle treatment, Treating 39 patients who had summed up unending torment ${ }^{43}$. Forty-six percent of the patients reported more conspicuous overhaul of their symptoms with this strategies than with any other kind of treatment they had previously gotten. Fifty-nine Percent found that needle treatment was more reasonable than some other activity based recovery. Sixty-nine percent of the patients who were dismembered were taking less medication. The Maker prescribes that needle treatment is as practical as ultrasonography, Cryotherapy and pharmaceutical. Berman and Colleagues raised in their review ${ }^{44}$ that there are a couple of issues raised however not sufficiently answered in the studies studied:

1. What is the long term effect of needle treatment? Can Support estimations keep up focal point in responders? 2. What is the perfect needle treatment for FM? 3. Does needle treatment work synergistically with energizer Arrangement?

All things considered, despite the positive results found, the Number of preparations related to the usage of needle treatment is still scanty, especially concerning FM treatment. Lee ${ }^{45}$ and Millea and Holloway ${ }^{46}$ appropriated productive Reviews of the material that had appropriated resulting to 1966 about the use of needle treatment in the treatment of unremitting misery. As demonstrated by Lee most of the studies have a poor Method. It is imperative to lead a greater number of Randomized, controlled studies, have a discriminating number of Patients and standardize the centers that are used ${ }^{47}$.

\section{LASER THERAPY}

The use of Light for healing has a history of thousands of year, but still there is a lot of work required in the field of Low Level Laser Therapy (LLLT) ${ }^{48}$. Laser therapy is the application of electromagnetic radiation with a combination of unique properties, which probably from the basis for a number of biological reactions. Laser light is a sort of non-natural light and produced by the amplification of 
light. Currently, number of LLLT in trend to treat painful conditions, like GaALAr, GaARandHeNe, theses lasers are non-thermal in nature, the depth of penetration of waves depends on the wavelength and it can bring physiological changes in the cellular functions, also known by the name of cold lasers ${ }^{49}$. Laser got the first approval by FDA (food and drug administration) in 2002, as the use of EPA's for the use of carpel tunnel syndrome and now various other syndromes and arthritis can be treated through it ${ }^{50}$. LLLT has been indicated to influence numerous sub cellular and cell forms, in spite of the fact that the components have not been all around characterized ${ }^{51}$. In any case, LLLT is unable to change the tissue temperatures significantly and it is a non-thermal modality ${ }^{52}$. LLLT has also been consumed for the treatment of various clinical problems; however no consents in regards to sign or viability have been created ${ }^{53-56}$. The Hardware, test outlines and systems utilized as a part of the Low-vitality laser writing are exceptionally variable and close consideration ought to be paid to treatment parameters when assessing What's more, contrasting these studies. Still, the viability of this treatment strategy is questionable. Various investigators have examined the reduction in pain with LLLT in intense and excruciating conditions, for instance, RA inflammation, osteoarthritis, Fibromyalgia, postoperative agony and low-back torment ${ }^{57-58}$. However, some have neglected to show such an impact in Excruciating musculoskeletal pathologies ${ }^{59-61}$. One of the histochemical research work has observed that there is increase in Prostaglandin after LLLT and hence limit the platelet accumulation and vasodilatation results ${ }^{62,63}$. Absence of Na-K- ATPase movement appears to increase Nociceptive motivation transmission; an increment in Na-K-ATP As taking after LLLT may be an element in agony lessening ${ }^{64-66}$. Due to the extensive number of positive reports and the Harmless nature of the treatments, further clinical assessment of laser treatment is justified. It is critical to recall that the writing on LLLT Studies is uneven and disarranged. Future works may indicate that outcomes now in clear clash are really distinctive Parts of the same issue. Case in point, it appears to be sensible that different tissues with disparate ingestion spectra could react distinctively to differing fortifying frequencies. Furthermore, errors in vitality measurements, treatment procedures What's more, treatment timetables may be sufficiently critical to Convolute assessment ${ }^{67,68}$.

\section{CONCLUSION}

Fibromyalgia is a syndrome which is too challenging to comprehend and treat effectively. Patients suffering with FM frequently look for substitution therapies, because of the ineffectiveness and dissatisfaction to the conventional and the therapies in the trend. A lot of work has been needed to understand the effective intervention to manage the signs and symptoms associated with FM. Although many results have been found in favor of the use different modalities related to physical therapy treatment for FM but still specific use of modalities like TENS, biofeedback, magneto and electromagnetic therapies is still a question. Treatment should be given according to the need of patient, targeted symptoms and functional impairments. In order to increase the chances of improvement the positive attitude of physician towards the patient and his/her problem and their families shows significant results. By reviewing all the above literatures it has been concluded that there is a need of more systemic and larger RCTs to appraise the effectiveness of physical agents and electrotherapy modalities in patients suffering from FM.

\section{REFERENCES}

[1] Wolfe F, Smythe HA, Yunus MB, Bennett RM, Bombardier C, Goldenberg DL et al. American College of Rheumatology, Criteria for the Classification of Fibromyalgia. Arthritis Rheum. 1990 Feb;33(2):160-72.

[2] Wolfe F, Ross K, Anderson J, Russell IJ, Hebert L. The prevalence and characteristics of fibromyalgia in general population. Arthritis Rheum. 1995; 38:19-28.

[3] Schochat T, Croft $P$, Raspe H. Epidemiology of firbromyalgia. Br J Rheumatol 1994;33:783-786.

[4] Moldofsky H. Sleep, Neuroimmune and Neuroendocrine functions in fibromyalgia and chronic fatique syndrome. Adv Neuro immunol 1995; 5:39-56.

[5] Gur A, Karakoc M, Erdogan S, Nas K, Cevik R, Sarac AJ. Regional cerebral blood flow and cytokines in young females with fibromyalgia. Clin Exp Rheumatol 2002;20:753-60.

[6] Littlejohn GO, Weinstein C, Helme RD. Increased neurogenic inflammation in fibrositis syndrome. J Rheumatol 1987; 14: 1022-5.

[7] Richard S, Cleare A. Treating fibromyalgia. Rhematology 2000;39: 343-346.

[8] Gur A, Karakoc M, Nas K, Cevik R, Sarac J, Demir E. Efficacy of low power laser therapy in fibromyalgia: a single-blind, placebo controlled trial. Laser Med Science 2002;17:57-61.

[9] Sprott H, Franke S, Kluge H, Hein G. Pain treatment of Fibromyalgia with acupuncture. Rheumatol International 1998; 18:35-36.

[10] Sprott H. What can rehabilitation interventions achieve in patients with primary fibromyalgia? Curr Opin Rhematol 2003;15:145-150.

[11] Offenbacher M, Stucki G. Physical Therapy in the treatment of fibromyalgia. Scand J Rhematol 2000; 29(Suppl 113):78-85.

[12] Pioro-Boisset M, Esdaile JM, Fitzcharles M. Alternative Medicine use in fibromyalgia syndrome. Arthritis care Res 1996:9:13-17.

[13] Rehan K. Alternative treament of RA. http://wwW.spineuniverse.com/conditions/spinal-arthritis/rheumatoid-arthritis/alternative-treatments-rheumatoid-a rthritis

[14] Baranowsky J, Klose p, Musial F, Hauser W, Dobos G, Langhorst J, Qualitative systemic review of RCT on complementary and alternative medicine treatments in Fibromyalgia. Rheumatol International. 2009;30(1): 01-21

[15] Chandola HC, Arunangshu, Fibromyalgia and Myofascial Pain Syndrome - A Dilemmma. Indian J anasesth. Oct 2009;53(50):575-81

[16] Grant AE. Massage with ice in the treatment of [painful conditions of musculoskeletal system. Arch Phy Med 1964;25:233-237.

[17] Speer KP, Warren RF, Horowitz L. the efficacy of cryotherapy in the postoperative shoulder. J Shoulder and Elbow Surg 1996;5(1):62-68.

[18] Matsushita K, Masuda A, Tei C. Efficacy of Waon therapy for fibromyalgia. Epub. Aug, 2008;47(16):1473-6.

[19] Lehman J, Delateur B, Warren C, Stonebrigde J. Heating of joint structures by ultrasound. Arch Phys Med Rehab 1968;49:28-30.

[20] Gur A. Physical therapy Modalities I management of fibromyalgia dept of physical medicine and rehab. 
Turkey current pharmaceutical design. 2006; 12:29-35.

[21] Citak-Karakaya I, Akbayrak T, Demirturk F, Ekici G, Bakar Y. Short and long term results of CT manipulation and combined ultrasound therapy in patients with fibromyalgia. JMPT. 2006; 29 (7):524-528.

[22] Almeida TF, Roizenblatt S, Benedito-Silva AA, Tufik S. The effect of combined therapy on pain and sleep in fibromyalgia. Pain J. 200:104(3):665-672

[23] Offenbacher M. Stucki G. Physical therapy in the treatment of fibromyalgia. Scand J Rheumatol 2000; 29:78-85

[24] Minor MA, Sanford MK. The role of physical therapy and physical modalities in pain management. Rheum Dis Clin N Am 1999;25:233-248

[25] Di Benedetto P, Iona LG, Zidarich V. Clinical evaluation of Sadenosyl-L methionine versus TENS in primary fibromyalgia. Curr Ther Res 1993;53: 2229.

[26] Basford JR. the clinical and experimental status of LLLT, Critical Review. Phys Rehab Med 1989;1.

[27] Veintraub MI. Complementary and alternative methods of treatment of neck pain. Phy Med Rehab Clin N Am 2003; 14:659-674

[28] Trock DH, Electromagnetic fields and magnets, investigational treatment for MSK disorders. Rheum Dis Clin North Am 2000;26:51-62

[29] Ferraccioli G, Ghirelli L, Scita F, Nolli M, Mozzani M, Fontana $S$, et al. EMG-biofeedback training in fibromyalgia syndrome. J Rheumatol 1987; 14L820-825.

[30] Buckelew SP, Conway R, Parker J, Deuser WE, Read J, Witty $T E$, et al. Biofeedback/relaxation training and exercise interventions for fibromyalgia, a prospective trial. Arth Care res 1998; 11:196-209.

[31] Molina A, Cecchettin M, Fontana S. Failure of EMG-biofeedback (EMG-BF) after sham BFB training in fibromyalgia (A 1357). Fed Proc 1987;46:549

[32] Burckhardt C. Non pharmacologic management strategies in fibromyalgia. Rheum Dis Clin North Am 2002;28:291-304

[33] NIH Consensus Conference on Acupuncture. JAMA 1998:280:1518-24.

[34] Waylonis GW. Long-term follow-up on patients with fibrositis treated with acupuncture. Ohio State Med J 1977; 73:299-302.

[35] Sprott H, Jeschonneck M, Grohmann G, Heim G. Microcirculatory changes over the tender points in fibromyalgia patients after acupuncture therapy (measured with laser-doppler flowmetry). Wien KlinWochenschr 2000;1 12:580-86.

[36] Targino RA, Imamura MHS, Kaziyama HHS, Souza LP, Hsing WT, Imamura ST. Pain treatment with acupuncture for patients with fibromyalgia. Curr Pain Headache Rep 2002;6:379-83.

[37] Deluze C, Bosia L, Zirbs A, Chantraine A, Vischer TL. Electro acupuncture in fibromyalgia: results of a controlled trial. BMJ 1992;305:1249-52.

[38] Patkar AA, Bilal LS, Masand PS. Management of fibromyalgia. Curr Psychiatry Rep 2003;5:218-24.

[39] Berman BM, Ezzo J, Hadhazy V, Swyers JP. Is acupuncture effective in the treatment of fibromyalgia? J Fam Pract 1999:48: 213-18.

[40] Vickers A, Zollman C. ABC of complementary medicine: acupuncture. BMJ 1999:319:973-76.

[41] Sandberg T, Lundeberg T, Gerdle B. Manual acupuncture in fibromyalgia: a long-term pilot study. J Musculoskel Pain 1999:7:39-58.

[42] Sandberg M, Lindberg LG, Gerdle B. Peripheral effects of needle stimulation (acupuncture) on skin and muscle blood flow in FM. Eur J Pain 2004;8: 163-171.

[43] Waylonis GW. Long-term follow-up on patients with fibrositis treated with acupuncture. Ohio State Med J 1977; 73:299-302.

[44] Berman BM, Ezzo J, Hadhazy V, Swyers JP. Is acupuncture effective in the treatment of fibromyalgia? J FamPract 1999:48:213-18.

[45] Lee TL. Acupuncture and chronic pain management. Ann Acad Med Singapore 2000;29:17-21

[46] Millea PJ, Holloway RL. Treating Fibromyalgia. AmFam Physician 2000; 62:1575-82.

[47] Targino RA, Imamura MHS, Kaziyama HHS, Souza LP, Hsing WT, Imamura ST. Pain treatment with acupuncture for patients with fibromyalgia. Curr Pain Headache Rep 2002;6:379-83.

[48] Wallace LB. Light therapy. In: Novey DW, editor. Clinician's complete reference to complementary and alternative medicine. Mosby, Philadelphia 2000;154-63.

[49] Veintraub Ml. Complementary and alternative methods of treatment of neck pain. Phys Med Rehabil Clin N Am 2003; 14:659-74.

[50] Veintraub Ml. Complementary and alternative methods of treatment of neck pain. Phys Med Rehabil Clin N Am 2003; 14:659-74.

[51] Basford JR. The clinical and experimental status of low-energy laser therapy. Crit Rev Phys Rehabil Med 1989;1:1-9.

[52] Brown AW, Weber DC. Physical agent modalities. In: BradomRL (ed.) Physical Medicine and Rehabilitation. WB Saunders, London, 2000:440-58

[53] Basford JR., Malanga GA, Krause DA, Harmsen WS. A randomized controlled evaluation of low-intensity laser therapy: Plantar fasciitis. Arch Phys Med Rehabil 1998;79:249-54.

[54] Craig JA, Barlas P, Baxter GD, Walsh DM, Allen JM. Delayed onset muscle soreness: Lack of effect of combined phototherapy/ low-intensity laser therapy at low pulse repetition rates. J Clin Laser Med Surg 1996; 14(6):375-80.

[55] Mokhtar B, Baxter GD, Walsh DM, Bell AJ, Allen JM. Double blind, placebo-controlled investigation of the effect of combined phototherapy/ low-intensity laser therapy upon experimental ischaemic pain in humans. Lasers Surg Med 1995; 17(1):74-81.

[56] Bülow PM, Jensen H, Danneskiold-Samsoe B. Low power Ga-AlAs laser treatment of painful osteoarthritis of the knee. Scand J Rehab Med 1994;26: 155-59

[57] Fischer AA. New developments in diagnosis of myofascial pain and fibromyalgia. Phys Med Rehab Clin North Am 1997;8:1-27.

[58] Gur A, Karakoç M, Çevik R, Nas K, Sarac AJ, Karakoc M. Efficacy of low power laser therapy and exercise on pain and functions in chronic low back pain. Lasers Surg Med 2003;32(3):233-8.

[59] Krasheninnikoff $M$, Ellitsgaard N, Rogvi-Hansen B, Zeuthen A. No effect of power laser in lateral epicondylitis. Scand J Rheumatol 1994;23(5):260-63.

[60] Mulcahy D, Mc Cormack D, McElwain J, Wagstaff S, Conroy C. Low-level laser therapy: a prospective double blind trial of its use in an orthopaedic population. Injury 1995;26(5):315-17.

[61] Thorsen H, Gam AN, SvenssonBH, Jess M, Jensen MK, Piculell I, et al. Low level laser therapy for myofascial pain in the neck and shoulder girdle. A double-blind, cross-over study. Scand J Rheumatol 1992;21:139-42.

[62] Calderhed RG. Report of Meeting of the American Society for Lasers in Medicine and Surgery: Arlington, 
Virginia, April 1989;15-17.

[63] Enwemeka CS, Rodriquez OO, Gall NG, Walsh NE. Morphometrics of collagen fibril populations in $\mathrm{He}-\mathrm{Ne}$ laser photo stimulated tendons. J Clin Laser Med Surg 1990;8:47-51.

[64] Kudoh C, Inomata K, Okajima K. Effects of $830 \mathrm{~nm}$ gallium aluminium arsenide diode laser radiation on rat saphenous nerve sodium-potassium-adenosine triphosphatase activity: a possible pain attenuation mechanism examinated. Laser Ther 1989;1:63-67.

[65] Trelles MA, Mayao E, Miro L. The action of low reactive level laser therapy (LLLT) on mast cell. Laser Ther 1989;1:27-30.

[66] Mizokami T, Aoki K, Iwabuchi S. Low reactive level laser therapya clinical study: relationship between pain attenuation and the serotonergic mechanism. Laser Ther 1993;5:165-8.

[67] Hina D, Brunner R, Landthalar M. Animal experiments in light induced wound healing. Laser Basic Biomed Res 1982;22:1-3.

[68] Mester E, Toth N, Mester A. The bio stimulative effect of laser beam. Laser Basic Biomed Res 1982;22:4-7. 